http://dx.doi.org/10.4314/gjl.v6i3.2

\title{
A SOCIOLINGUISTIC ANALYSIS OF KINSHIP TERMS IN LIKPAKPALN (KONKOMBA)
}

\author{
Abraham Kwesi Bisilki
}

\begin{abstract}
This study, synchronically, describes and explicates the phenomenon of kinship terms in Likpakpaln, a Gur member of the Niger-Congo phylum, spoken mainly in the northern parts of Ghana. It focuses on the addressive usage of kinship terms. I use observation (both participant and non-participant) as a principal ethnographic data collection technique, supplemented by the semi-structured interview, informal conversation and my native speaker introspection. The analysis of data is informed by Dell Hyme's ethnography of communication as a theoretical frame. Based on the data analysed, I argue that kinship addresses in Likpakpaln can be categorised into three major types: agnatic, matrilateral and affinal kinship address forms, of which matrilateral and affinal kinship addresses are by complementary filiation. I also show that communicative ends have a significant influence on the vocative usage of kinship terms in interlocution among the Bikpakpaam (the Konkomba people). I further argue that the repertoire of Likpakpaln kinship addresses and the pattern of usage of these kinship addresses in communicative interactions is greatly tied to the Bikpakpaam kinship structure and social universe. Finally, I observe that there is a perceptible level of intercultural intrusion on the kinship address terms used among the Bikpakpaam.
\end{abstract}

Key terms: Sociolinguistic analysis, kinship terms and Likpakpaln

\section{Introduction}

The arena of address terms is one that has enjoyed flourishing scholarly attention in sociolinguistic investigations (Dickey, 1997: 255; Afful, 2006a: 275). The significant interest level shown in address terms seems to find a unanimous justification by many 
researchers that address terms play a very important role in human communication and society. For instance, Mashiri (1999: 93-94), in a study of terms of address among the Shona of Zimbabwe, maintains that terms of address serve as conduits of communicating the values and expectations of groups, individual beliefs, fears, hopes and attitudes. On a similar note, Bonvillain (2000: 83-89), establishes that address terms play a crucial function in communication, social interaction and cohesion. Deriving from the foregoing claims is the fact that studies on address terms have, consistently, proved useful in providing a panoramic view into the nature of societies and cultures. Following this, one cannot, but further concur with Afful (2006b: 76) that address terms are an important feature of the interface between language and society. Thus, address terms are a focal resource in sociolinguistics, the study of relations between language and society.

Nonetheless, it has been observed that whereas there are an admittedly everincreasing number of studies on address terms, a majority of such studies are based on Anglo-American, Euro-Asian and Latin American milieus. On the contrary, a relatively few of such works explore address phenomena in African contexts and, for that matter, Ghana (Afful, 2006a: 277). As by Afful, the body of sociolinguistic research on Ghanaian languages is partitionable into two: those on Akan and those on non-Akan, of which the literature on Akan is seen to be far more enhanced than that on the non-Akan linguistic systems. The present study, by being pitched on the Likpakpaln linguistic culture, adds to the non-Akan wing of the literature.

It is also no exaggeration to say that there are, scarcely, available studies specifically on address terms among the Bikpakpaam (speakers of Likpakpaln/the Konkomba people). The apparent rarity of linguistic documentation on address terms relating to the Bikpakpaam ethno-linguistic group is, probably, a reflection of the attested under-documentation of their language and culture (Maasole, 2006; Schwarz, 2009). Whereas there is little researched about the Likpakpaln language and culture, many of the speaker communities, including Kpassa and Sibi (all in the Nkwanta North District of Northern Volta, Ghana) where data for the present study were collected, are becoming highly cosmopolitan, a situation being triggered by modern urbanization and globalization trends.

In response to the afore-highlighted situation, this study is staged as a documentation of Kinship terms (KTs) as an address phenomenon in Likpakpaln while also contributing to the expansion of relevant knowledge on address systems in African linguistic contexts. Given its positioning, the study, as well, carries relevant implications for trans-ethnic and intercultural communication in the rapidly ever globalising world. 
Additionally, the present paper also registers its own voice in the ever-evolving theoretical discourse surrounding Brown's (1965) famous Invariant Norm of Address (INA). Brown's Invariant Norm of Address has been described as a re-statement of a claim earlier made by Brown and Ford (1961) that the major determinants of address choices are status and intimacy (Quin, 2008: 409). As argued by Brown, the Invariant Norm of Address is to constitute a culturally universal principle about addressing. This principle is more elaborately stated as: the linguistic form used for an inferior in dyads of unequal status is used in dyads of equal status among intimates and that the linguistic form used for a superior in dyads of unequal status is used in dyads of equal status among strangers. The position of the present study is that whereas one cannot underestimate the role of status and intimacy variables in the choice of address terms, communicative intentions also significantly regulate address choices in interlocution. Beyond this, it is also made clear in the present study that address terms are quite versatile and the same address category can be contextually manipulated into communicative functions deemed typical of some other address types.

\section{Theoretical Framework}

This study is situated in the ethnography of communication (Hymes, 1964/1974). Consequently, it draws on the inspiration that any investigation of the problems of language must call to attention the need for fresh kinds of data and also attention to the essence of investigating directly the use of language in contexts of situation so as to discern patterns proper to speech activity. Further, such an approach must take as context a community, investigating its communicative habits as a whole. That way, any given use of channel and code takes its place as but part of the resources upon which members of the community draw (Hymes, 1964: 3).

It is communication that must provide the frame of reference within which the place of language in culture and society is to be described. The same linguistic means can be organised for quite differing communicative ends while it is also true to say that the same communicative ends may be served by significantly varied linguistic forms. Facets of the cultural values and beliefs, social institutions, roles and personalities, history and ecology of a community must be examined together in relation to communicative events and patterns as focus of study (Hymes 1964: 3). This aspect of the ethnography of communication is particularly relevant to my present task, as the study tries to examine how one category of address terms (Kinship addresses) can be communicatively organised 
and used towards different communicative goals. As well, the study explores how communicative intentions/goals can influence speakers to deploy kinship address forms in conversation. In doing so, I also pay attention to how socio-cultural values, beliefs, norms and practices of speakers are interlaced with the phenomenon of kinship addresses (KAs).

Also, this study takes a theoretical basis in Hymes' (1974) model of the ethnography of communication. In this theoretical paradigm, Hymes proposes that every communicative event has eight crucial factors to consider: setting $(\mathrm{S})$, participants $(\mathrm{P})$, Ends (E), act sequence (A), key (K), instrumentalities (I), norms of interaction and interpretation $(\mathrm{N})$ and genre $(\mathrm{G})$. The linkage between this study and Hymes' model is to the extent that the present study pays attention to how participant relationships and communicative ends/goals determine kinship address choices and usage in Bikpakpaam communication.

\section{Methodology}

Field work for this study lasted 6 months in all. The field sessions were September to December, 2013 and June to August, 2014. The field settings included Kpassa and Sibi, all in the Nkwanta North District of Northern Volta, Ghana. These communities are among the most well-known traditional settings of the Bikpakpaam where authentic data that reflect the Bikpakpaam people's knowledge of their language and culture can be ascertained. I use observation (both participant and non-participant) as the main data instrument in sociolinguistic ethnographies (Levon, 2013: 196; Wardhaugh, 2006: 249) and complement this data method with the semi-structured interview, the informal conversation and my native speaker introspection. This also aided an analysis of the phenomenon from both etic and emic points of view. The interview engaged 8 purposively sampled participants ( 4 male and 4 female), aged 40 and above. In addition to a-40-year minimum age threshold, the purposive selection also required that a consultant was a native speaker of Likpakpaln and should have continuously resided in the local community for, at least, the past 20 years. The interviews were mostly used to elicit a catalogue of Likpakpaln kinship terms (LKTs) and to also ascertain whether or not there were definite overt social norms that mediated the usage of Kinship address (KA) in Likpakpaln. Informal conversation served chiefly as a mechanism for cross-checking and further probing of data and information gleaned. The observation took place in 26 communicative contexts, covering interactional domains such as family settings, market contexts, funeral occasions, arbitration sessions at chiefs' palaces, marriage dispute resolution proceedings and religious ceremonies (table 1 represents the communicative domains and frequencies of 
observation). The 26 observations were beside the other opportunistic scenarios that I took advantage of. The domains for observation were carefully chosen to ensure that the data was representative of varied participant and social domains of language use. 312 instances of actual usage of KAs in natural discourse were recorded and analysed within the ethnography of Communication (Hymes, 1964/1974). For each kinship address instance recorded, I further inquired and noted down the actual kinship relationship between the interactants. Attention was also paid to the relative ages of interlocutors in the particular exchanges recorded.

Table 1 Distribution of Observed Communicative Domains

\begin{tabular}{|l|l|}
\hline Domain & Frequency of Observation \\
\hline Family & 8 \\
Funeral & 5 \\
Market & 4 \\
Chief's palace (arbitration) & 3 \\
Marriage dispute resolution & 2 \\
Religious ceremony & 4 \\
\hline & \\
\hline
\end{tabular}

\section{The Bikpakpaam Lineage and Clan System}

The Bikpakpaam are, historically, an acephalous voltaic people in northern Ghana, among whom are other ethnicities such as the Lobi, the Gurunsi, the Kusasi, the Sissala etc. As a Voltaic people, the Bikpakpaam's original location in Ghana is in the western part of the Oti River system where they spread over an area up to $50 \mathrm{~km}$ wide and $175 \mathrm{~km}$ from north to south (Middleton \& Tait, 1958; Tait, 1961; Barker, 1991). In the Oti plain area, Saboba is often regarded as the traditional centre of the Bikpakpaam. As a true representation as this may be, the Bikpakpaam are also currently well represented in many other parts of Ghana (see Immigration and Refugee Board of Canada [GH], 1996) where in several cases they have indigenised and hold sway in certain settlements. Kintampo and Atebubu in the Brong Ahafo and the Nkwanta Districts in Northern Volta are some of the areas where Bikpakpaam are well represented in population terms. The Bikpakpaam are located in latitude 7.94653 and longitude 1.02319. Simons and Fennig (2017) in 
Ethnologue: Languages of the world estimate that the Bikpakpaam population in Ghana alone is 831000 .

The Bikpakpaam is a highly segmentary tribe in socio-politico outlook (Middleton \& Tait, 1958: 1). The society is segmented into clans and lineages founded on unilineal descent groups. In the Bikpakpaam social sphere, a lineage is an agnatic descent group and between lineages of one clan, an agnatic relationship is assumed (Tait, 1961: 72). Each clan is a system of lineages, which in themselves are genealogical structures. Under the superordinate clan, there is the major lineage, decomposed into two or three minor lineages and the minor lineage into a number of nuclear lineages. Again, the major lineage consists of agnatic kin descended from an apical ancestor, three or four generations from the surviving compound head. In a similar fashion, a minor lineage is two or three generations between an apical ancestor and the living compound head. A nuclear lineage, on the other hand, is an agnatic group from an apical ancestor in the father or grandfather of living compound heads.

A Bikpakpaam clan can be unitary, compound or contrapuntal, the latter being attributable to disjunctive and expansionistic migrations Barker, 1991). The traditional residential style in the Bikpakpaam clan system is one clan per district. In other terminologies, the district, in this sense, is a parish or a hamlet. A member of the Bikpakpaam society speaks of his/her clan referentially as doyaab and addressively as $\mathbf{N}$ doyaab. This term cognates in Tait (1961) as dejaa.

In spite of the fact that it is patrilineal ties that receive emphasis among the Bikpakpaam, the individual's concomitant relations with matrilateral and affinal kin cannot also be ignored. The existence of these relationships is crystallised in a number of matrilateral as well as affinal rights and duties imposed on a member of the Bikpakpaam society (Barker,1991:9). For instance, one may say that there is a very weak form of avuncularism among the people where a sister's son can be called to assist on the farm of the mother's brother.

Although socio-cultural paradigms continue to drift, the Bikpakpaam lineage and clan system is yet to see any considerable metamorphosis.

\section{Kinship Terms: The Referential Versus the Addressive}

Among the multiplicity of definitions targeted at explaining address terms is the view that an address term is a word or phrase that is used for the person being talked to or written to, Yule (2006), cited in Esmae'li (2011). Yule's definition, though simplistic, tends to be more appealing as it caters for both verbal and non-verbal forms of communication. 
Other definitions of address terms as feature in Afful (2006a), Oyetade (1995) and Keshavarz (2001), among others, seem to have a limitation by circumscribing address terms solely to oral, face-to-face interaction. Another view by Bonvillain (2000: 83) has it that address terms, also known as terms of address include several linguistic types and forms that can be used to name, refer to or address a participant in a communicative situation.

A distinction is struck between the referential and the vocative or address functions of linguistic expressions. While such a distinction is well asserted in the literature, it is also admitted that there is no absolute transparent relationship between referential and vocative usage. Address and reference tend to share a lot of tendencies, a situation which throws a great challenge at any attempt to set the two clearly apart. For instance, just as it is impracticable to attempt to determine the way a given individual is normally referred to, so it is with trying to figure out the usual way that a person is addressed. Both reference and address for an individual vary according to the speaker and convey the speaker's relationship to the addressee or the referent. Again, in many cases, a term that is used in reference to a person is also maintained as an address to him/her. For example, a child's parent may refer to him as John when talking to the child's teacher and still retain John in an address context to the child at home.

On the obverse side of this argument, addresses and references are parameterised on a number of points. First and foremost, the same speaker may use separate forms in reference and in address to the same person. For instance, a Ghanaian student may refer to his teacher as Mrs. Akoto, but address her as Madam. Again, the referential meaning of a word may be at variance with its addressive interpretation such that a referentially denigratory term can become neutral in an address respect. Afful (2006b: 86) instantiates the case of the Akan derogatory form, kwasea (stupid) in an address rendered as Kwasea Boy among a student clique at the University of Cape Coast (UCC), Ghana. He also demonstrates how otherwise apparently derogatory English forms like Naughty Boy and Foolish Man feature as acceptable addressives in verbal exchanges of student in-groups at UCC. As shown by Afful, these descriptive phrases, in their denotation as insults, are divested of such meaning in communicative encounters and, thus, are invested with some tinge of neutrality.

It probably stands to say that the only functional means to perceiving the thin line between the referential and the vocative usage of linguistic forms is when the phenomenon is subjected to a synchronic, socio-pragmatic analysis (see Dickey 1997). Nonetheless, in a basic sense, a word assumes an addressive or vocative status when it is used to directly 
call a co-participant in communication, but referential when it serves as a reference label. In this sense, therefore, the vocative usage of a term is how it is used in a context to call an intended decoder/recipient of a message while the referential sense relates to how the person being talked about is termed. Illustratively, this means that if A communicates to $\mathrm{C}$ about $\mathrm{B}$, the set of terms $\mathrm{A}$ uses to denote $\mathrm{C}$ will stand as addresses/addressives whereas A's terms denoting B will most likely serve as referential items.

$\mathrm{KTs}$, as a set of linguistic expressions, function both as referential and address terms in communication. It is the addressive usage of kinship terms that this study is slanted towards.

\section{The Lexicon, form and Context of Likpakpaln Kinship Addresses}

KTs are linguistic expressions that are used for relations, whether of consanguineous or complementary filiation ties. They are indicative of the relationship between a person and his relatives (Yang, 2010: 738). In a related sense and for suitability to the research context of this study, I explain kinship addresses as nominal vocatives that are mainly used to call one's relatives in speech.

Likpakpaln kinship addressives (LKAs) are generally nominal forms. In this sense, therefore, Likpakpaln kinship terms have a categorial semblance with Akan (Akan is a majority ethnolinguistic group in Ghana) honorific terms, except that the latter further incorporates (a few) pronominal items (Agyekum, 2003: 370). The repertoire of LKAs is open-ended only in the sense of lexical borrowing. This means that membership of the repertoire does not easily lend itself to addition either by derivation or other processes, except through borrowing as a result of intercultural contact. Thus, one can say that it is basically by lexical borrowing that the stock of LKAs is susceptible to linguistic and cultural dynamism. A KT in Likpakpaln has two related forms for referential and addressive usages respectively: either a base or a stem form, prefixed with a syllabic and pronominal clitic N-, which I analyse in an address situation as the genitive, my. The vocative form of a kinship term in Likpakpaln invariably necessitates prefixing the $\mathrm{N}$ pronoun to the item involved. For example, the item $\mathrm{N}$-ti (my father) is not in an addressive sense without being preposed with $\mathrm{N}$-. Consequently, a KT without the $\mathrm{N}$ - assumes a referential status. Hence, the terms, Ti (father), $\mathrm{Na}$ (mother), Ninkpan (sister) and Yaaja (grandfather) are the forms used in reference as against N-na (my mother), N-ninkpan (my sister) and $\mathrm{N}$-yaaja (my grandfather) which constitute the addressive forms. This structure of LKAs is analogous to forms Dickey (1997: 262) describe as kinship terms with possessive modifiers. Usually, if the base of a kinship term begins with a bilabial, the N- 
pronominal prefix undergoes a homorganic nasal assimilation when attached to a KT with a bilabial initial, resulting in an $\mathbf{M}$ - as in $\mathbf{M}$-beil (my elder brother), $\mathbf{M}$-puul (my aunt, i.e. father's sister/paternal aunt). A KT, whether as an addressive or referential form can be suffixed with - the class $2 \mathrm{a}$-tiib ${ }^{1}$ to mark plurality (see Winkelmann, 2012: 473-5 for Likpakpaln noun classes).

An interesting observation, from the data for this study, is that one cannot rely on only the form of a kinship term to determine its communicative function as an address or a reference term. It is noted that whereas kinship terms in address contexts constantly go with the N-/M- prefix, such forms also occur in some referential usages. The conversational exchanges below evince the foregoing communicative reality with the use of Likpakpaln kinship terms:

1. A: Hey! U-bu wei, a-cha la chee?

Hey! CL.1-child DEM 2SG-go.PROG where LOC

'Hey! This child, where are you going to?'
B: $\quad \mathrm{N}=$ na
ntum
$\mathrm{mi}$
GEN;SG=mother
send.PRF
1SG.OBJ
ke
n
ti-daa ti-waan.
to-buy.IPFV CL.21-thing
'My mother/my mum has sent me to buy something.'

2. A: $N=$ na, kp sa sambal ya wii!

GEN;SG=mother, look.PRS 2SG.POSS plate DEF crack.PRF

'My mother/my mum, look, your plate is cracked!
B: $\quad \mathrm{N}=$ kan.
$\mathrm{Fu}$
ya
Yesterday
nka

li
fi lir
$1 \mathrm{SG}=$ see.PRF.
DEF
CONN

3i
TRM fall.PRF
ki-tin.
CL.12,15-ground
'I have seen it. It fell on the floor/ground yesterday.'

\footnotetext{
${ }^{1}$ Likpakpaln kinship terms in their root/base forms are placed under noun class $1 \mathrm{a}$ and in class $2 \mathrm{a}$ when in their plural, but referential form.
} 
As can be observed, in 1 above, B uses $\mathrm{N}$-na as a reference term while in 2 the same form, $\mathrm{N}$-na is used addressively by A. However, the absence of the $\mathrm{N}-/ \mathrm{M}$ - pronominal clitic in a kinship term, irrespective of context, is invariably suggestive of referential usage. One can, therefore, postulate that the determination of referential and addressive uses of Likpakpaln KTs rests on both the linguistic (morphological) form and communicative context. This can be schematically represented as: form + context $=$ function of a KT.

Every Likpakpaln kinship address used in a communicative encounter inherently indexicalises the relative social personae of the interactants as well as suggest the type of relational bond existing between them. This phenomenon with LKAs is in tandem with a resounding argument in the literature that terms of address are extremely important conveyers of social information and reflect interpersonal relationships (Qin, 2008: 409410). Social information here can be about individuals in a dyad or aspects of the sociocultural cosmology. Generally, a LKA will include, in its composite semantic interpretation, age, gender and type of kin relationship between the addresser and the addressee. It must, nevertheless, be noted that the age and the relational meanings suggested in a kinship address is not to always be taken literally on every occasion of use. For example, a woman is supposed to address each of her father-in-law's wives as N-chapii (an address term for husband's mother), regardless of the relative age of the addressee to the addresser. This also happens, as in other cultures, when adults/parents sometimes invert addresses with children so that a child is addressed by a parent as father, mother etc. (Aliakbari \& Toni, 2008; Mashiri, 1999). The relational semantic also commonly assumes a non-literal sense in a context of extension of a kinship address to a non-relative.

The set of linguistic expressions that serve as kinship addresses (KAs) in Likpakpaln are very much tied to the kinship system of the speakers. This linguistic reality is, once again, in line with the age-long theoretical notion that language use is socioculturally determined (Wardhaugh, 2006: 221-224) whereas culture also finds expression through language. By their status as linguistic items, address terms have been shown to have their roots in the socio-cultural context of society (Oyetade, 1995; Aliakbari \& Toni, 2008). Every LKA form chosen in a given context affirms one of three possible kinship relations: agnatic, matrilateral and affinal relation types. This falls in with the Bikpakpaam social dispensation whereby every individual born into the community, by default, acquires three categories of kin. These include paternal relatives, matrilateral relatives and affinal relatives. Although the Bikpakpaam operate a unilineal agnatic system of descent (Zimon, 2003: 429), the social order also places on the individual the responsibility of giving a certain threshold of social recognition for his/her matrilateral and affinal kin. 
Delineating LKAs into three, namely, agnatic, matrilateral and affinal finds plausibility in the fact that every KA in the Likpakpaln repertoire non-neutrally point to a particular kind of relationship that is bounded within three kin types, although the matrilateral and the affinal KAs can be regarded as complementary since they are supposed to be meant for the non-descent members of an addresser. As will be discovered in the following section/s, LKAs, whenever they are employed in speech, are largely marked for these separate kin groups to the ego. This feature of bifurcation in Likpakpaln kinship terminologies is more clearly pronounced in the distinction that they mark between matrilateral and agnatic relatives. I diagrammatically represent the classification of LKAs as in the figure below:

\section{Types of Likpakpaln Kinship Addresses}

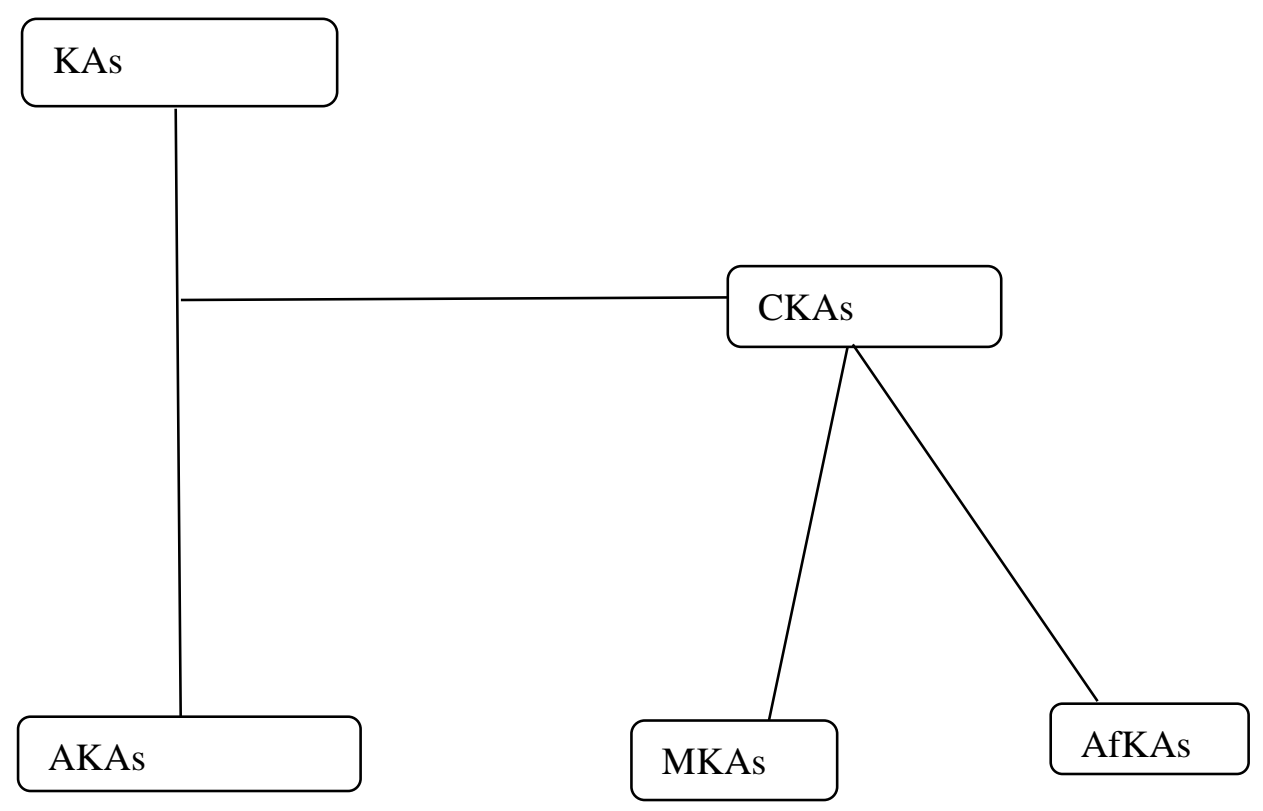

Figure 1: Likpakpaln Kinship Addresses 


\subsection{Agnatic Kinship Addresses (AKAs)}

AKAs are the vocatives that reflect a patrilineal relationship between interlocutors. Given the strong patrilineal inclination of the Bikpakpaam society, one will further define AKAs as the KAs proper that are employed in address to members of one's descent. This category of KAs was observed to be the most commonly used among the Bikpakpaam. This can be attributed to an aspect of the social philosophy and practice among the Bikpakpaam. In the Bikpakpaam society, the legitimate kin to dwell among are one's paternal relatives and it is usually considered weird and deviant for one (particularly men) to take up a long-term residence with uterine or affinal relatives. It is, nonetheless, worthwhile indicating that the ${ }^{2}$ Bikpakpaam practise virilocality and so women are expected to live in their husbands' communities. This situation finds enforcement in a kind of strict patrilineal territoriality among the Bikpakpaam. This finds corollary in Tait (1961: 73; Barker 1991: 7) that, as far as the Bikpakpaam habitation is concerned, one clan occupies one district and that patrilocal maximal lineages reside in contiguous hamlets. Ideally, one may only go to one's matrilateral kin when the occasion demands and so do married men keep visits to their affinal kin sparingly. This social norm and residential pattern naturally restricts the frequency of interlocutory engagements between matrilateral and affinal relatives as compared to such engagements with agnatic kin. It appears that the influence of kinship notion and practice on the use of LKAs is in compliance with the refrain in several related investigations that terms of address are significantly affected by history, social relationships and traditional ethics (Quin 2008; Yang 2010; Ismae'li 2011). Further still, this is reminiscent of Hymes' (1964) tenet that communicative events and patterns are best examined in relation to cultural values, beliefs, social institutions etc.

AKAs are not employed in a unidirectional mode in Bikpakpaam communication. In a verbal interaction, AKAs are sometimes used reciprocally in trans-gender and in crossgenerational fashions between participants. Addressing among the Bikpakpaam lacks accompanying strict social sanctions. However, from a general point of view, the younger agnatic kin of a clan tend to more frequently address their elderly relatives with AKAs than the vice versa. There is infrequent use of AKAs in verbal engagements occurring between agnatic relatives in the same age ranks, even when such interlocutions are trans-gender. Traditionally, the use of AKAs in dyads between age mates may only be a deliberate recipe to a certain desired communicative effect. What rather happens in some instances is for

\footnotetext{
${ }^{2}$ In figure 1, KAs = kinship addresses, AKAs = agnatic kinship addresses, CKAs = complementary kinship addresses, MKAs = matrilateral kinship addresses and AfKAs $=$ affinal kinship addresses.
} 
some youths to resort to forms like Braa/Brada (bro./brother) and Sista (sister) as a mark of respect/politeness or unfamiliarity. These forms (which originate from English) may be used in isolation or used to precede the addressee's FN as in Braa Mukanjo, Sista Nakool etc. as can be noticed in the following exchanges:

\section{A: Braa Jangboja, ndopua.}

Bro. Jangboja, good morning

'Bro. Jagbonja, good morning.'

\section{B: Monica, lafei bi?}

Monica, health be.there

'Monica, how are you?
4. A: Braa, u-nachipuan
Bro., CL.1-young man

$$
\begin{array}{ll}
\mathrm{u}=\mathrm{ti}=\mathrm{si}=\mathrm{na} & \text { yin } \\
\mathrm{who}=\mathrm{LOC}=\text { stand.PROG=FOC } & \text { call.PROG }
\end{array}
$$

si.

\section{SG.OBJ}

'Bro., the young man standing over there is calling you.'

B: Yoo, $\quad$ aa $=$ ni $=$ li-tuln

Ok, 2SG=and=CL.5-work

'Ok, thank you.'

The form, Braa can be used either in isolation or together with FN while Brada is often used alone. It is observed that when this pattern of $\mathrm{KA}+\mathrm{FN}$ is used for a youth, there is a dignifying/respectability effect on the addressee. Braa in isolation may suggest politeness or lack of familiarity with the addressee's personal name while Brada in isolation is mostly indicative of unfamiliarity with addressee's name. This English-source address forms are clearly on ascendancy in African communities. ${ }^{3}$ Afful (2006b) and Mashiri also confirm the use of similar addresses among the Fante of Ghana and the Shona of Zimbabwe respectively. Table 1 below provides a list of AKAs:

\footnotetext{
${ }^{3}$ Among the Bikpakpaam, people are seldom addressed with the last name(LN) or with the formal full name as in first name, plus last name (FNLN). The use of FN is the order of the day. LN and FNLN patterns usually occur in non-traditional contexts like in school, at the hospital, in church etc.
} 
Table 2: Agnatic Kinship Addresses (AKAs) ${ }^{4}$

\begin{tabular}{|l|l|l|}
\hline Kinship Address & Addresser - Addressee & English Gloss \\
\hline Nyaaja & $\mathrm{C} \Longrightarrow \mathrm{FF}$ & Grandfather \\
\hline Nti & $\mathrm{C} \Longrightarrow \mathrm{F}$ & Father \\
\hline Ntikpel & $\mathrm{C} \Longrightarrow \mathrm{FBe}$ & Uncle \\
\hline Ntiwaa & $\mathrm{C} \Longrightarrow \mathrm{FBy}$ & Uncle \\
\hline Mpuul & $\mathrm{C} \Longrightarrow \mathrm{FZ}$ & Aunt \\
\hline Mbeil & $\mathrm{B} \Longrightarrow \mathrm{Be}$ & Elder brother \\
\hline Nnaal & $\mathrm{B} \Longrightarrow \mathrm{By}$ & Younger brother \\
\hline Mbeil & $\mathrm{Z} \Longrightarrow \mathrm{Ze}$ & Elder sister \\
\hline Nnaal & $\mathrm{Z} \Longrightarrow \mathrm{Zy}$ & Younger sister \\
\hline Nninkpan & $\mathrm{B} \Longrightarrow \mathrm{Z}$ & Sister \\
\hline Nninja & $\mathrm{Z} \Longrightarrow \mathrm{B}$ & Brother \\
\hline Njapuan & $\mathrm{F} \Longrightarrow \mathrm{S}$ & Son \\
\hline & & \\
\hline
\end{tabular}

\footnotetext{
${ }^{4}$ The kinship addresses in Tables 2, 3 and 4 may not be exhaustive of the repertoire in Likpakpaln. However, all those that appeared in the research data are represented. The kin notations used in the tables were derived from Raciunaite-Pauzuoliene (2013: 103) and are interpreted as follows: F-father, B-brother, S-son, H-husband, e-older/elder, ss-same sex, M-mother, Z-sister, D-daughter, W-wife, y-younger and osopposite sex. A combination of symbols expresses possession (e.g., MZ means mother's sister and FBe means father's brother younger than father). A double pointing arrow ( $\Longleftrightarrow$ ) suggests that both addresser and addressee can exchange the kinship address.
} 


\begin{tabular}{|l|l|l|}
\hline Mbisal & $\mathrm{F} \Longrightarrow \mathrm{D}$ & Daughter \\
\hline Mpubil & $\mathrm{FZ} \Longrightarrow \mathrm{C}$ & Nephew/Niece \\
\hline Nyaabil & $\mathrm{F} \Longrightarrow \mathrm{SC}$ & Grandchild \\
\hline
\end{tabular}

In Likpakpaln, there are no separate AKAs for immediate and distant lineage or clan members. AKAs in Likpakpaln remain the same, for both immediate and distant relatives. For example, the addresses, Ntikpel (my elder paternal uncle) and Ntiwaa (my younger paternal uncle) are invariant for both immediate and non-immediate male paternal siblings of one's father. This address culture mirrors an aspect of the communalistic character of the Bikpakpaam society where every child belongs to every adult clan member and every adult clan member a parent to every child in the clan. In this regard, Tait (1961: 74) has this to say about the Bikpakpaam: "To any child the elder is my father; any child of the lineage is my child to the elder."

Another unique discovery around LKAs is that parents hardly address their own genetic children with the exact address forms that reflect the parent-child relationship as in Mbisal (my daughter) or Njapuan (my son). Parents prefer to use such addresses to the children of other relatives other than their own. When one decides to address one's own child with a KA, one will usually resort to non-literal usage of address such as addressing a child with Ntiwaa, Nti, Mpuul, Nna etc. This amounts to a pattern describable as reversative addressing since, at the moment of address, parents seem to invert their address positions with their children. Otherwise, FN is the commonest address form from parents to their genetic children.

\subsection{Matrilateral Kinship Addresses (MKAs)}

MKAs are the terms that are used in address to one's mother's patrikin or mother's agnates. The term Nweitiib is the hyperonym that collectively addresses or refers to all of one's matrilateral kin as the form, Weitiib is invariably the reference form for such relations. Among the Bikpakpaam, the use of KAs in communication is more stable and regular in matrilateral relationships than happens in agnatic relationships. This is to say that matrilateral relatives, across generations and gender tend to more regularly observe the use of appropriate KAs in their interactions than agnatic relations do. For instance, whereas 
uterine kin in the same ranks will still prefer to address one another with KAs, same generation agnatic kin rarely use KAs, with the most prevalent address form being the exchange of FN. It is likely that this address situation is underpinned by a relatively reduced level of familiarity (conditioned by the Bikpakpaam social norms) among matrilateral kin. It was observed that with the exception of one's direct matrilateral grandparents (i.e. parents of one's mother) who will normally address one by FN, all other matrilateral kin will prefer to address one with an appropriate MKA, with the vice versa being the case. Table 3 provides a list of Likpakpaln MKAs, built from the research data.

Table 3: Matrilateral Kinship Addresses (MKAs)

\begin{tabular}{|l|l|l|}
\hline Kinship Address & Addresser- Addressee & English Gloss \\
\hline Nyaaja & $\mathrm{DC} \Longrightarrow \mathrm{MF}$ & Grandfather \\
\hline Nyaaja & $\mathrm{BZC} \Longrightarrow \mathrm{MFB}$ & Grandfather \\
\hline Nwei & $\mathrm{ZC} \Longleftrightarrow \mathrm{MB}$ & Uncle \\
\hline Nnakpel & $\mathrm{ZC} \Longrightarrow \mathrm{MZe}$ & Aunt \\
\hline Nnawaa & $\mathrm{ZC} \Longleftrightarrow \mathrm{MZy}$ & Aunt \\
\hline Nwei & $\mathrm{MBS} \Longleftrightarrow \mathrm{FZC}$ & Cousin \\
\hline Nnabo & $\mathrm{MZC} \Longleftrightarrow \mathrm{MZC}$ & Cousin \\
\hline Nnawaa & $\mathrm{MBD} \Longrightarrow \mathrm{FZC}$ & Cousin \\
\hline
\end{tabular}

As can be noted from Table 3, Likpakpaln matrilateral KTs have a feature of skewing as it lumps relatives of different generations with the same label. For example, the kinship address used for one's mother's brother (MB) is the same for one's mother's brother's son (MBS). It has been established that this nature of kin terms is common with ethnicities with strong patrilineal systems (Schwimmer 2001), a description that the 
Bikpakpaam social system is prototypical of. Also, as with the Likpakpaln agnatic kin terms, uterine kin terms do not discriminate between immediate and distant relatives.

\subsection{Affinal Kinship Addresses (AfKAs)}

Affinal kinship addresses (AfKAs) are a set of addresses that portray a marital relationship between interlocutors. Observation and data revealed that females (women) more often use AfKAs to males (men) than the reverse happens. It means, then, that a husband's kin exact more AfKAs from the wife than a wife's kin do from the husband. Again, this in-balance in the pattern of kinship address usage is partly explainable in the Bikpakpaam type of marital residence, patrilocality. Whereas a wife usually will spend the rest of her life in the midst of her husband's relatives, it is the norm that a husband infrequently mingles with the wife's relatives. This limits communicative opportunities that would warrant the exchange of AfKAs between husband and his wife's kin. Although it is socially and culturally very approving for the individual (whether male or female) to address the kin of his/her spouse with the appropriate AfKAs, the Bikpakpaam have no known mechanism in place to exact compliance to this expected verbal behaviour from members of the community. One may never address one's spouse's relatives in the ascending generations with a bare $\mathrm{FN}$, but an instance of a violation of this norm may not also lead to any comment or open rebuke.

The use of AfKAs among the Bikpakpaam is more of a mark of politeness in deference to one's affinal relatives. In the Bikpakpaam tradition, respect between an individual and his/her affinal kin may not always be mutual. It is customary for wives and husbands as individuals to show more meekness and greater respect towards the kinsmen of their spouses. This hypothesis has a backing in the Bikpakpaam philosophy that: Ukpakpanja achoo san waawumbor (A man's in-law is his God). Thus, the use of AfKAs by an individual to the kin of his/her spouse is mostly motivated by negative politeness. Table 4 below catalogues Likpakpaln AfKAs.

Table 4: Affinal Kinship Addresses (AfKAs)

\begin{tabular}{|l|l|l|}
\hline Kinship Address & Addresser - Addressee & English Gloss \\
\hline Nchoo & $\mathrm{H} \Longleftrightarrow \mathrm{WF}$ & Father-in-law/Son-in-law \\
\hline
\end{tabular}


Bisilki: A Sociolinguistic Analysis of Kinship Terms in Likpakpaln (Konkomba)

\begin{tabular}{|l|l|l|}
\hline Nchoo & $\mathrm{H} \Longleftrightarrow \mathrm{WM}$ & Mother-in-law/Son-in-law \\
\hline Nchoja & $\mathrm{W} \Longrightarrow \mathrm{HF}$ & Father-in-law \\
\hline Nchapii & $\mathrm{W} \Longleftrightarrow \mathrm{HM}$ & Mother-in-law \\
\hline Mpuu & $\mathrm{H} \Longleftrightarrow \mathrm{W}$ & Wife \\
\hline Nchal & $\mathrm{W} \Longleftrightarrow \mathrm{H}$ & Husband \\
\hline Nyon & $\mathrm{W} \Longleftrightarrow \mathrm{HW}$ & Rival \\
\hline Nchakpel & $\mathrm{W} \Longleftrightarrow \mathrm{HBe}$ & Brother-in-law \\
\hline Nchawaa & $\mathrm{W} \Longleftrightarrow \mathrm{HBy}$ & Brother-in-law \\
\hline Nchiin & $\mathrm{H} \Longleftrightarrow \mathrm{WB}$ & Brother-in-law \\
\hline Nchiin & $\mathrm{H} \Longleftrightarrow \mathrm{WZ}$ & Sister-in-law \\
\hline Nnato & $\mathrm{H} \Longleftrightarrow \mathrm{WZH}$ & Brother-in-law \\
\hline
\end{tabular}

As a consistent feature of Likpakpaln KTs, AfKAs do not mark distinction between close and distant relatives. For instance, the addressing term, Nchoja for husband's father (HF) is the same for husband's father's brother (HFB) of any generation. Also, a notable address mannerism in relation to AfKAs among the Bikpakpaam is that couples almost never address each other with the forms Mpuu (my wife) and Nchal (my husband), which terms would depict the exact kinship relationship between them. The most regular way of addressing between couples is reciprocal FN. Some wives may also, in exchange for FN, address their husbands with occupational titles like Fiita (fitter), Teila (tailor), Tiicha (teacher) etc. The use of teknonyms from wives to husbands is also visible among the Bikpakpaam. In this particular addressing style, a husband is addressed by wife with a form that defines him as 'father of his child'. In the Bikpakpaam case, it is usually the first child's name that is adopted in this descriptive address from wife to husband. Examples of this 
address pattern include: Mboti Ati (Mborti's Father), Abena Ati (Abena's Father), Njofuni Ati (Njofuni's Father) etc.

There is also an evolving address paradigm of some couple using Mama (mum/mummy) and Daddi/Dada (daddy/dad) in address to each other (i. e., wife addresses husband as Daddi and gets Mama in return), though not always in a reciprocal form as some husbands, in such address situations, still keep FN for their wives. This innovation in Likpakpaln kinship terminologies is a mark of Westernism in the socio-cultural context of the Bikpakpaam as happens in the Akan address system (Agyekum, 2006:229). So far, couples who were discovered to patronise this novel form of addressing fulfilled some or all of these variables: Christianity, exposure to urban life and attainment of some level of formal education.

\section{Functions of Kinship Addresses}

Convincingly, address terms have been shown to carry several functions in communication and society generally. In the view of Quin (2008: 409), terms of address open communicative acts and set the tone for the interchanges that follow. For Leech (1999), they signal transactional, interpersonal and deitic ramifications in human relationships. Similarly, Afful (2006b: 89) argues that by terms of address, students attempt to construct and reflect individual and group social identities. However, a trajectory that is innovative with this study is to look at how a single address category (in this case, kinship address terms) can communicatively be manipulated to assume functions typical of other address types. Further to this claim, this study also makes the point that the choice and use of an address form can determine as well as be determined by the communicate intent of an addresser.

\subsection{Kinship Addresses as Identifiers}

Identification is a common function that is known of address terms. This role of address terms seems to be more closely related to personal names, a sub-class of address terms. One of the reasons for naming in our cultural contexts is so that we can differentiate (Agyekum, 2006: 207) and a name refers specifically to its bearer.

A primordial communicative significance of Likpakpaln KAs is their (KAs) resourcefulness in identifying participants in a communicative encounter when used nonfictively. This identity can be from an intra-clan or an inter-clan perspective. In the 
Bikpakpaam society, an individual simultaneously has three categories of relatives (see section 5) in the midst of numerous clan divisions. Given this social arrangement, the choice of a kin term for an addressee helps identify his/her lineage or clan line. For example, if it is known that A's mother belongs to clan $x$, the use of the address form, Nwei to B by A will reveal that B is a member of clan $\mathrm{x}$. In the same way, when B is in the company of A's clansmen, the use of the address form, Nwei alone suffices to identify and single out B as the one being addressed.

In their use for an identification motive, KAs are also commonly combined with FN, in which case the particular address takes the structure of KA + FN. This happens when the addresser can gauge that $\mathrm{FN}$ alone is inadequate in identifying an intended recipient. Among the Bikpakpaam, it is ubiquitous for the same FN to have multiple bearers in the community or even in the same household. This is especially the case with Christian/English, Islamic and Akan day names that have become very common among the Bikpakpaam. When this happens, one functional way to avoid and resolve addressee ambiguities is for an addresser to add a KA to the addressee's FN as in Nwei Magmanbi, Ntikpel Timunaan, Nnawaa Ubaneen etc. For this kind of addressee identification strategy $(\mathrm{KA}+\mathrm{FN})$ to work, the addresser must have kinship tie/s with addressee/s. The following exchanges exemplify KA + FN usage:

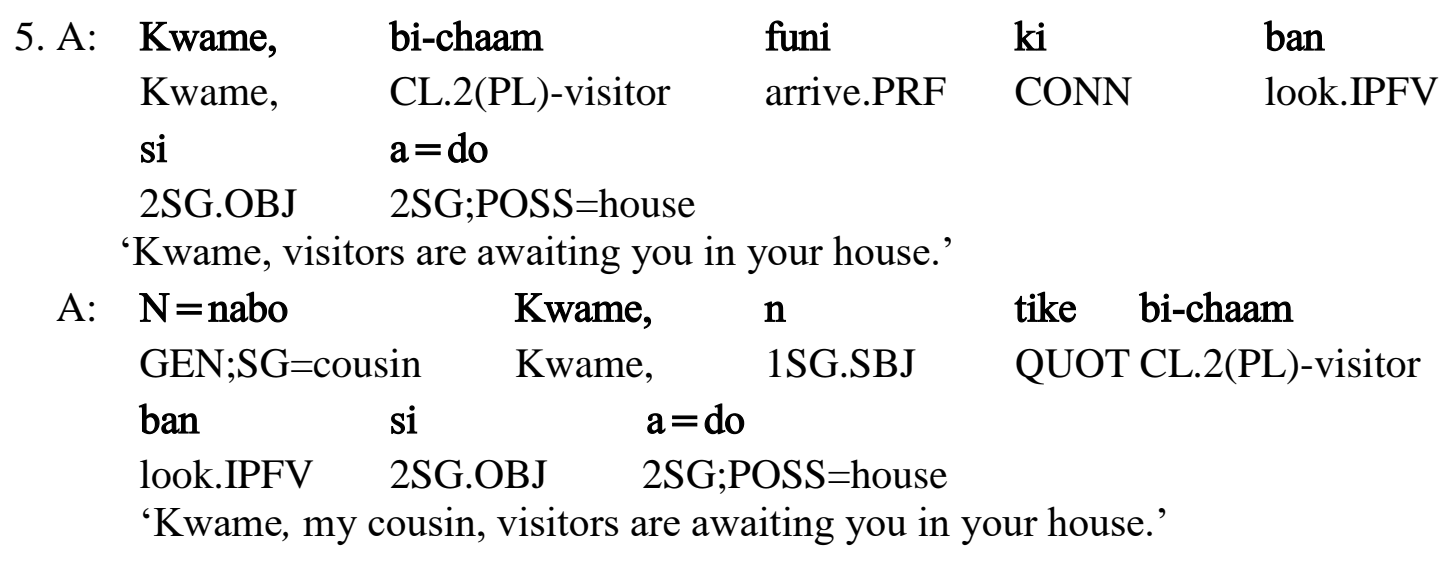
B: Ma ba-nyi ke mme chee nka a=len.
1SG;NEG PST-know that $1 \mathrm{SG}$ there that 2SG=talk.PRF Aa $=$ ni=lituln 2SG=and=CL.1-work


'I didn't know that I was the one you were talking to. Thank you.'

In 5, A had to do an address repair in A's second utterance by adding a KA to B's (addressee's) FN in order to sufficiently identify B as the recipient. In the company of other Kwame FN bearers, B did not know he was the one being addressed until a MKA, Nnabo was added.

\subsection{Kinship Addresses as Solidarity Terms}

KAs provide a very potent means of creating and sustaining solidarity among members of the Bikpakpaam community. This is seen among some clansmen using certain KA forms reciprocally as a mark of intimacy and to drum home a sense of belongingness. The AKA form, Ntiwaa was seen to have such a use among the Binajuub clansmen at Sibi. It is usual for any two members, particularly males to trade the form, Ntiwaa upon meeting each other. This symmetrical address exchange is mostly accompanied by noticeable feelings of elation, warmth and oneness. Other forms that were commonly used that way include the MKA form, Nnabo/Nnays and the AfKA form, Nnato. The dyads below exemplify the solidarity use of KAs. ${ }^{5}$
6. A: $\mathrm{N}=$ tua!
GEN;SG=uncle
'uncle!'
B: $\mathrm{N}=$ tua!
GEN;SG=uncle
'uncle!'
A: $N=$ tua, $\quad$ ka $\quad$ ti $\quad$ lan-ji ba din?
GEN;SG=uncle CONN 1PL.SBJ FUT-eat what today
'Uncle, what are we going to eat today?'
B: $\quad \mathrm{N}=$ tua, $\mathrm{n} \quad \mathrm{kpe} \quad \mathrm{a}=\mathrm{b}$.
GEN;SG-uncle, 1SG.SBJ look.IPFV 2SG=on
'Uncle, I'm looking up to you.'

\footnotetext{
${ }^{5}$ The conversation in 5 above was recorded at the Binajuub community, Sibi during a funeral festivity. Both A and B are members of the Binajuub clan and are also cousins, i.e. A's mother and B's mother are sisters.
} 


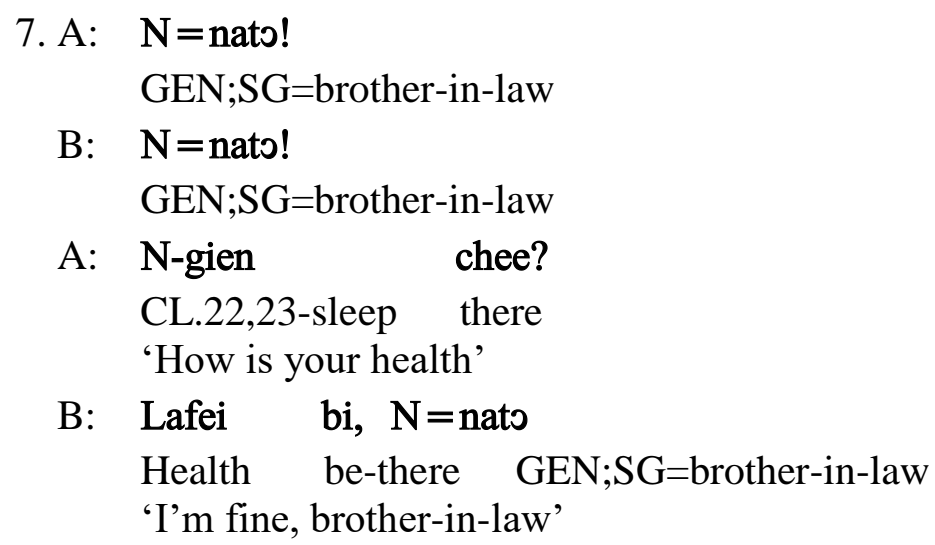

Every Likpakpaln KA can possibly be adopted for a solidarity effect between individuals or groups, especially in communication between same generation interlocutors. An already existing camaraderie between interlocutors can inform their use of a KA to reinforce this bond. The other way around, a sense of solidarity can be initiated by using a KA either to a relative or a non-relative. For example, the use of the form, Nnato (whether literally or non-literally) somewhat naturally engenders a feeling and attitude of solidarity between the addresser and the addressee. In their typical use as solidarity terms as in 6 and 7 above, Likpakpaln KAs assume the outlook of Gang and play names (see Agyekum, 2006: 225 for gang and play names).

\subsection{Honorific Use of Kinship Addresses}

Honorifics are linguistic markers or forms that signal respect (Bonvillain, 2000: 89). Making reference to the views of other writers, Agyekum (2003: 369) refer to honorifics as specialised address and deference forms used to show politeness. Honorifics also point to aspects of social identity and reflect social asymmetries. Likpakpaln KAs are sometimes used as reverential titles, in which case they attain honorific status. Some elderly people by virtue of their achievements and exemplary life styles in the community may come to deserve a high level of respect. One way of expressing this respect is for the other people to address such an individual with either Tina (our mother), Titi (our father), Tiyaa (our grandmother) or Tiyaaja (our grandfather). Prefixing a KA with the plural genitive, Ti- (our) elevates the status of the addressee as the parent of all. This honorific use of Likpakpaln KAs is akin to the use of bóbö (elder paternal uncle) among the Chinese. As 
noted by Bonvillain (p. 88), the use of the Chinese bóbö implies a deferential and exalted status of the addressee, worthy of extreme respect and the concomitant humbling of the speaker.

The honorific usage of Likpakpaln KAs is also extended to supernatural beings in the Bikpakpaam religious circles and activities. In prayer, God is sometimes addressed as Titi Uwumbor (God our father) and in libation an ancestor/ancestress is addressed honorifically as Tiyaaja/Tiyaa + name of ancestor or ancestress. In an honorific mode, a KA can be used alone or in combination with the personal name of the addressee. An honorific usage of a KA in Likpakpaln may also have a laudatory under-tone as it dignifies the addressee.

\subsection{Emotive Use of Kinship Addresses}

The emotive use of language refers to the use of language to appeal to people's feelings or emotions (Ofori, Asilevi \& Quansah, 2013: 27). In this case, I consider the emotive function of language in a positive sense where KAs are used to trigger positive feelings and attitudes that elicit desirable responses. It also incorporates the use of KAs as a mark of approval for a deserving act or conduct.

Some of the emotive uses of Likpakpaln KAs include their functions as persuasive, affectionate/endearment and commendatory devices in communication. A careful observation reveals that KAs have a persuasive force that can skilfully be drawn on by an addresser to elicit behavioural compliance from an addressee. In a broader perspective, persuasion is any form of discourse that serves to influence thought, feeling and conduct. One way that Likpakpaln speakers achieve persuasion with KAs is to extend to an addressee an address form that elevates his/her status relative to the addresser. The following dialogue between a mother and her 5-year old son exemplifies this:
8. A: Foo
n-nyok
ki nyo
Take.PRS
CL.3-medicine
and drink

'Take medicine and drink.' (mother giving medicine in a cup to her sick son)
B: Maa lan-nyo
1SG;NEG FUT-drink
'I won't drink!




$\begin{array}{llllll}\text { A: } & \text { Ah! N=yaaja, } & \text { fo } & \text { ki nyo } & \text { ka } \\ \text { Ah! GEN;SG=grandpa } & \text { take.PRS } & \text { and } & \text { drink.PRS } & \text { CONN } \\ \text { a = wun } & \text { nson }^{6} & & & \\ \text { 2SG.POSS=body cool } & & & \\ \text { 'Ah! Grandpa, take it so that you'll get well'. } & \end{array}$

KAs are also commonly used among the Bikpakpaam as endearment/affectionate and commendatory expressions. This is mostly from parents to children and from husbands to wives. However, in such instances, there is a precondition of a pleasurable mood, especially on the part of the addresser. The endearment/affectionate and commendatory uses of KAs also mainly see the use of the addresses in a non-literal sense. For example, a husband may, as a mark of affection or commendation address his wife as Mpuul (a KA for paternal aunt), Nyaa, Nnawaa etc.

\section{Conclusion}

In this paper, I have discussed kinship terms as a category of addressives in Likpakpaln. I also put forth the proposal that, per their addressive usage, Likpakpaln kinship terms can be delineated into three, namely: agnatic kinship addresses, matrilateral kinship addresses and affinal kinship addresses. This categorisation is dependent on the kind of kinship ties that are constructed by the Bikpakpaam social system. Also, more importantly, I have shown that in addition to the popular claim in the Invariant Norm of Address (Brown, 1965) that the choice of addresses in communication is solely based on status and intimacy, communicative intentions can also significantly influence address choices. Further, I intimate that the same address type (in this case kinship address terms) can be contextually manipulated into varied communicative functions. This observation ties up with a focal point in the ethnography of communication (Hymes, 1964) that the same linguistic form can be organised for quite varied linguistic ends. Finally, I hint that some innovative tendencies are creeping into the Bikpakpaam address system, a situation that marks intercultural influence on the Bikpakpaam linguistic culture.

\footnotetext{
${ }^{6}$ After speaker A's second utterance in 8 , her sick son (B) now grabs the cup and begins to sip the medicine.
} 


\section{References}

Afful, J. B., 2006a. Address Terms among university students in Ghana: A case study. Language and Intercultural Communication 6.1: 76-91.

Afful, J. B., 2006b. Non-kinship address terms in Akan: A sociolinguistic study of language use in Ghana. Journal of Multilingual and Multicultural Development 27.4: 275-289.

Agyekum, K., 2003. Honorific and Status Indexing in Akan Communication. Journal of Multilingual and Multicultural Development 24.5: 369-385.

Agyekum, K., 2006. The Sociolinguistic of Akan personal names. Nordic Journal of African Studies 15.2: 206-234.

Arliakbari, M. \& Toni, A., 2008. The Realisation of address terms in modern Persian in Iran: A Sociolinguistic Study. Linguistik Online 35.3: 3-12.

Barker, T. R., 1991. Small bands of strangers: The contraposed lineage. Anthropos, 86, 1.3: 1-18.

Bonvillain, N.,2000. Language, culture and communication. New Jersey: Prentice Hall.

Brown R. \& Ford, M., 1961. Address in American English. Journal of Abnormal and Social Psychology 62: 375-385.

Brown, R., 1965. The basic dimensions of interpersonal relationship. In R. Brown, ed., Social Psychology. London \& New York: Free Press, pp. 51-100.

Dickey, E., 1997. Forms of address and terms of reference. J. Linguistics 33: 255-274.

Esmae'li, S., 2011. Terms of address usages: The case of Iranian spouses. International Journal of Humanities and Social Sciences 1.9: 183-188.

Hymes, D., 1964. Introduction: Towards ethnographies of communication. Anthropologist 66.6: 134.

Hymes, D., 1974. Foundations in sociolinguistics: An ethnographic approach. Philadelphia: University of Pennsylvania Press.

Immigration and Refugee Board of Canada [GH]. 1996. Information on where the Konkomba tribe reside and on their tribal or mother language. DOI: http://www..refworld.org/docid/3ae6a251c.html

Kesharvaz, M. H., 2001. The role of social context, intimacy and distance in the choice of forms of address. International Journal of Soc. and Lang. 148: 5-18.

Levon, E., 2013. Ethnography and recording interaction. In R. J. Podesva \& D. Sharma, eds., Research Methods in Linguistics. New York: Cambridge University Press, pp. 195-215.

Maasole, C. S., 2006. The Konkomba and their Neighbours in the Pre-European Period up to 1914: A Study in their Ethnic Relations in Northern Ghana. Accra: Universities' Press.

Mashiri, P., 1999. Terms of Address in Shona: A sociolinguistic approach. Zambezia 26.1: 93-110. 
Middleton, J. \& Tait, D., eds., 1958. Tribes without rulers: Studies in African segmentary systems. London: Routledge and Kegan Paul.

Ofori, K, Asilevi, K, \& Quansah, C., 2013. Basic linguistics. Winneba: Institute of Educational Development and Extension.

Oyetade, O. S., 1995. A Sociolinguistic Analysis of Address Forms in Yoruba. Language in Society 24: 513-535.

Quin, X., 2008. Choices in terms of address: A sociolinguistic study of Chinese and American English practices. In K. M. Chang \& H. Kang, eds., Proceedings of the $20^{\text {th }}$ North American Conference on Chinese Linguistics, 1: 409-421.

Raciunaite-Pauzuoliene, R., 2013. Cultural Anthropology: Dialectal guidelines. Kaunas, Lithunia: Department of Cultural Studies, Vytatau Magnus University.

Schwarz, A., 2009. How many focus markers are there in Konkomba? In M. Masangu et. al., eds., Selected Proceedings of the $38^{\text {th }}$ Annual Conference on African

Linguistics: Linguistic Theory and Language Documentation. Somerville, MA, pp. 182192.

Schwimmer, B., 2001. Systematic kinship terminologies. Department of Anthropology, University of Manitoba.

Simons, Gary F. \& Fennig Charles, D., eds., 2017. Ethnologue: Languages of the world $\left(20^{\text {th }}\right.$ ed $)$. Dallas: SIL International.

Tait, D., 1961. The Konkomba of Northern Ghana. London: Oxford University Press.

Wardhaugh, R., 2006. An introduction to sociolinguistics. $5^{\text {th }}$ ed. Oxford, UK: Blackwell Publishing

Winkelmann, K., 2012. D 4. Konkomba (Likpakpaln). In G. Miehe et al., eds., Noun class systems in Gur Languages Vol. 4: North Central Gur Languages. Cologne: Köpe, pp. 472486.

Yang, C., 2010. Translation of English and Chinese addressing terms from the cultural aspect. Journal of Language Teaching and Research 1.5: 738-742.

Yule, G., 2006. The study of language. $3^{\text {rd }}$ ed. UK: Cambridge University Press.

Zimon, H., 2003. The Sacredness of the Earth among the Konkomba of Northern Ghana. Anthropos 98: 421-443. 